NBER WORKING PAPER SERIES

\title{
BENEFIT INCIDENCE WITH INCENTIVE EFFECTS, MEASUREMENT ERRORS AND LATENT HETEROGENEITY: \\ A CASE STUDY FOR CHINA
}

\author{
Martin Ravallion \\ Shaohua Chen \\ Working Paper 21111 \\ http://www.nber.org/papers/w21111 \\ NATIONAL BUREAU OF ECONOMIC RESEARCH \\ 1050 Massachusetts Avenue \\ Cambridge, MA 02138 \\ April 2015
}

Financial support for the survey data collection for this study was provided by the World Bank's Knowledge for Change Trust Fund. For their comments the authors are grateful to Alan de Brauw, Dave Coady, Margaret Grosh, Daniel Hammond, Dominique van de Walle and participants at the Annual Bank Conference on Development Economics, 2013, World Bank. The findings, interpretations and conclusions of this paper are those of the authors, and should not be attributed to their employers, the World Bank, or the National Bureau of Economic Research.

NBER working papers are circulated for discussion and comment purposes. They have not been peerreviewed or been subject to the review by the NBER Board of Directors that accompanies official NBER publications.

(C) 2015 by Martin Ravallion and Shaohua Chen. All rights reserved. Short sections of text, not to exceed two paragraphs, may be quoted without explicit permission provided that full credit, including $\odot$ notice, is given to the source. 
Benefit Incidence with Incentive Effects, Measurement Errors and Latent Heterogeneity: A

Case Study for China

Martin Ravallion and Shaohua Chen

NBER Working Paper No. 21111

April 2015

JEL No. H22,I32,I38,O12

\begin{abstract}
In what is probably the largest cash transfer program in the world today China's Dibao program aims to fill all poverty gaps. In theory, the program creates a poverty trap, with $100 \%$ benefit withdrawal rate (BWR). But is that what we see in practice? The paper proposes an econometric method of estimating the mean BWR allowing for incentive effects, measurement errors and correlated latent heterogeneity. Under the method's identifying assumptions, a feasible instrumental variables estimator corrects for incentive effects and measurement errors, and provides a bound for the true value when there is correlated incidence heterogeneity. The results suggest that past methods of assessing benefit incidence using either nominal official rates or raw tabulations from survey data are deceptive. The actual BWR appears to be much lower than the formal rate, and is also lower than the rate implied by optimal income tax models for poverty reduction. The paper discusses likely reasons based on qualitative observations from field work. The program's local implementation appears to matter far more than incentives implied by its formal rules.
\end{abstract}

Martin Ravallion

Center for Economic Research

Georgetown University

ICC 580

Washington, DC 20057

and NBER

mr1185@georgetown.edu

Shaohua Chen

Lead Statistician

Development Research Group

World Bank

schen@worldbank.org 


\section{Introduction}

Most rich countries today have extensive welfare systems for which poverty reduction is an important objective and most emerging middle-income countries are embarking on new social policies with explicit antipoverty objectives. Concerns about incentive effects have long been prominent. Famously, such concerns were central to the early nineteenth century debates on England's Poor Laws, which provided targeted relief to the poor. The Poor Laws went back to around 1600, but their pinnacle was clearly the Speenhamland System of 1795, which aimed to guarantee a minimum income through a sliding scale of wage supplements (Himmelfarb, 1984). The view that such policies creating poverty was endorsed by prominent classical economists, including Malthus (1806) and Ricardo (1817). ${ }^{2}$ Significant reforms to the Poor Laws were implemented in 1834, including the repeal of Speenhamland.

While the Poor Laws debate was hugely influential on social policy, the evidence appears to have been largely based on easily manipulated anecdotes and characterizations, with flimsy claims of attribution. ${ }^{3}$ The arguments were somewhat one-sided, and many potential economic benefits were ignored. ${ }^{4}$ Nonetheless, the policy debate soon spread widely and has echoed over the last 200 years. Motivated by the debates on England's Poor Laws in the early $19^{\text {th }}$ century, and influenced by the writings of prominent British economists, similar debates were going on in the US, with calls for reforms to cut the rising cost of relief efforts largely motivated by claims about incentive effects (Klebaner, 1964). In modern times, Murray (1984) and others mounted an influential critique of US welfare policies in which similar concerns about adverse incentive effects loomed large. And, while modern debates on social policy have certainly had more evidence to draw on than was the case in the $19^{\text {th }}$ century debates on the Poor Laws, strong policy positions have persisted independently of the evidence. ${ }^{5}$

This long-standing debate about the incentive effects of targeted social policies is relevant to a major new antipoverty program in China. In an effort to address new concerns about unemployed and vulnerable workers, and the social instability that they might create, the central government introduced the Minimum Livelihood Guarantee program, popularly known as

\footnotetext{
${ }^{2}$ For further discussion of this debate in Ravallion (2014a).

3 The ale-house figured prominently in the anecdotes about behavioral responses; see Furniss (1920, Ch.6).

4 For further discussion see Solar (1995)

5 In the context of the 1980s debates on US welfare policy see Ellwood and Summers (1986). Moffitt (1992, 2002) and others noted the paucity of good evidence on incentive effects.
} 
the Dibao (DB) program, in 1999. ${ }^{6}$ The program's design is outlined in various documents of the State Council and it is administered by the Ministry of Civil Affairs (MOCA). By 2009 the program had expanded to cover 23 million people in urban areas, but it stabilized at this level after that. $^{7}$

This is China's version of Speenhamland. ${ }^{8}$ The DB program aims to provide locallyregistered urban households with an income per person below predetermined local DB "poverty lines" (Dibao xian) with a transfer payment sufficient to bring their incomes up to that line. ${ }^{9}$ So this is a program for which one's prior, based on the scheme's deign, would be that there are large incentive effects. Indeed, taken literally, the program's design implies that participants face a $100 \%$ benefit withdrawal rate (BWR) (or marginal tax rate) in that a small increase in nonprogram income will result in an equal reduction in program receipts. Incentives to escape poverty will be weak or absent. However, there are many reasons why the actual BWRs on an antipoverty program may differ from the nominal rate. ${ }^{10}$ While the State Council's proclamations imply a BWR on DB of $100 \%$ there is scope for local discretion and innovation. ${ }^{11}$

This paper studies the Dibao program with the aim of assessing whether it has created a poverty trap — whether it operates in practice the ways its formal rules suggest, implying a 100\% BWR. The bulk of the paper focuses on the problem of estimating the mean BWR, given by the average rate at which transfer receipts respond to differences in household income. As is recognized in the literature, the BWR is a key parameter for any social policy. ${ }^{12}$ This can be interpreted as a measure of targeting performance, telling us how much transfer receipts decline with higher pre-transfer income. Focusing on the BWR also allows us to draw on simulation results from the literature on optimal income taxation.

Most methods of calculating the BWR found in practice have either: (i) calculated the transfers/taxes implied by the formal rules, or (ii) calculated conditional means of actual

\footnotetext{
6 Dibao started in Shanghai in 1993, spread to other cities, and became a national policy in 1997, with formal State Council regulations issued in 1999. On the history and politics of the program see Hammond (2009, 2011).

${ }^{7}$ In 2007 a new rural version of the Dibao program emerged. In 2013 the rural program covered 54 million people. World Bank (2010) studies this program in its early stages in four provinces.

${ }^{8}$ It is also reminiscent of Britain's Supplementary Benefit introduced after the Second World War, whereby income top-ups aimed to assure that all incomes reached the poverty line.

${ }^{9}$ Obtaining permanent registration in a new location is generally a difficult and lengthy process in China (not least for the poor), so in practice DB eligibility is confined to well-established local residents.

${ }^{10}$ Moffitt (2002) makes this point in the context of welfare policies in the US.

11 This has been noted by Hammond $(2009,2011)$ and Duckett and Carrillo (2011).

12 See, for example, Moffitt (2002), Holt and Romich (2007) and Maag (2012). The BWR is the key parameter of interest in this context, although other parameters are of interest more broadly, such as labor supply elasticities.
} 
transfers/taxes at each level of net income, i.e., treating net income as fixed. ${ }^{13}$ It is wellrecognized that behavioral responses can invalidate either method. This is obvious for method (i). In method (ii), when net income, defined as gross income less transfers received or taxes paid, is taken to be income in the absence of the program one is ignoring behavioral responses. Measurement errors also come into play, such as due to miss-reporting of incomes. ${ }^{14} \mathrm{We}$ study the bias in statistical estimates of the BWR induced by latent incentive effects and income measurement errors.

The paper also identifies a third source of bias (not previously discussed in the literature to our knowledge), which we call correlated incidence heterogeneity. This arises when there are idiosyncratic differences in the BWR, correlated with income. For example, on moral grounds, program administrators in practice may resist cutting benefit levels of the poorest family when its income rises slightly. The extent of this problem will naturally vary with the amount of local administrative discretion in implementation.

The paper proposes an econometric estimator for the mean BWR for the Dibao program based on specially-designed surveys for the purpose of this paper. ${ }^{15}$ To assure that our proposed method is operational, we constrain it to use essentially the same data as the popular statistical accounting method using income net of transfers - assuming that income is fixed. Our key identifying assumption can be thought of as a more general, and more plausible, version of the fixed income assumption. Instead we allow only certain income components to be fixed, which become the instrumental variables for total income net of transfers/taxes. While less restrictive than the fixed-income assumption, our identification strategy is not beyond question. Correlated incidence heterogeneity can still leave a bias in our estimator, by creating correlations between the instrumental variables and the error term. We argue that this extra bias can be signed under the assumption that if the data we have are consistent with the program's aim of reducing poverty then the unobserved differences in incidence (stemming from heterogeneity in BWRs)

\footnotetext{
${ }^{13}$ This method (or some variation on it) is what Bourguignon and Pereira Da Silva (2003, p.9) term the "accounting method." Examples include Kakwani (1986), Atkinson and Sutherland (1989), Sahn and Younger, 2003) and Lustig et al. (2014). The method has the attraction of simplicity, in that the calculations are straightforward. However, net income (so calculated) need not accord well with income in the absence of intervention given behavioral responses. The potential for bias in assessments of benefit incidence is well recognized. See the discussion in van de Walle (1998).

${ }^{14}$ As Ravallion (2008) argues, what is identified as "imperfect targeting" in social programs could simply reflect such errors.

${ }^{15}$ While we apply the method here to a single program it could also be readily adapted to a collection of programs or even the complete tax-benefit system.
} 
will also be consistent with that objective. In other words, if what we observe indicates that the program reduces poverty then it is assumed that this is also true of the things we do not observe.

We argue that our identifying assumptions are plausible in this setting. Our results suggest that the way the DB program operates in practice through its local-level implementation greatly attenuates the incentive effects implied by its formal design. Thus the official nominal rules appear to be highly deceptive about actual incidence. While in theory, DB imposes a 100\% marginal tax rate on participants, the reality on the ground is a much lower rate. Using our data on DB participants and a matched comparison group of non-participants, we estimate that the BWR is only about $12-14 \%$ per annum. We find a higher BWR in richer cities, peaking at $27 \%$ for Beijing. It appears that (even in Beijing) the incentives built into the program as it works in practice are unlikely to create a poverty trap. Indeed, when viewed in the light of the literature on the optimal design of targeted programs, the program's BWR would appear to be too low.

The following section examines the problems of estimating the BWR and describes our solution. Section 3 describes the Dibao program and our data. Section 4 presents our results, also comparing our estimate of the BWR with the non-behavioral method. We offer some observations on the implications of our findings in Section 5. Section 6 concludes.

\section{Theory and methods of estimating the benefit withdrawal rate}

One can define the "benefit incidence" of a specific set of transfers (or taxes) as the mapping from incomes in the absence to those transfers to the transfer payments received. With little loss of generality we can think of this mapping as some unknown smooth function giving the transfer to household $i$, denoted $T_{i}$, with income in the absence of transfers $Y_{i}^{*}$; let this function be $\phi_{i}\left(Y_{i}^{*}\right)$. Note that the function varies, allowing transfer receipts to vary at a given $Y_{i}^{*}$. (A special case identifies the benefit incidence as the conditional mean transfer received at given income, i.e., the regression function of $T_{i}$ on $Y_{i}^{*}$.) We can then define the BWR as the local slope of the tangent to $\phi_{i}\left(Y_{i}^{*}\right)$, as given by $-\beta_{i}$ in the equation for the tangent: ${ }^{16}$

$$
T_{i}=\alpha_{i}+\beta_{i} Y_{i}^{*}
$$

\footnotetext{
${ }^{16}$ Notice that there is no error term in this equation since it holds by definition.
} 
To illustrate, consider the extremes of "perfect targeting" and "no targeting." With perfect targeting everyone is brought up to a minimum income level, $Z$, depending on their current income, i.e., $-\beta_{i}=1$ for all $i$ for which $Y_{i}^{*} \leq Z$ and $T_{i}=0$ otherwise. Such transfers will protect from income poverty, but create a poverty trap. Without rationing by the government, the cost of the program can be expected to rise above the aggregate poverty gap. On top of the fact that those receiving payments will have little or no incentive to work or acquire income from some other source, at least some of those not initially eligible (because their income exceeds the poverty line) will see an attractive income-leisure trade-off in that they could have only slightly lower income by working less and so becoming eligible.

At the other extreme, a "basic income scheme" provides a fixed cash transfer to every person, whether poor or not, i.e., $T_{i}=Z\left(\beta_{i}=0\right)$ for all $i .{ }^{17}$ This idea has spanned policyoriented discussions in both rich and poor countries. ${ }^{18}$ There are no incentive effects of the transfers since there is no action that anyone can take to change their transfer receipts. But nor is there any purposive targeting to poor people. While a basic income is unlikely to alter incentives to work (say), a complete assessment must take account of the method of financing the transfers, and once one allows for financing, the incentive and information issues re-emerge. Proposals in developed countries have typically allowed for financing through a progressive income tax scheme (such as in Meade, 1972), in which case the idea becomes formally similar to the Negative Income Tax (Friedman, 1962), though the modes of administration may differ.

In practice, we expect most programs to fall somewhere between these extremes. Intuitively, we can think about the policy choice as that of setting the trade-off between two main objectives of a social policy: First, the policy can provide insurance, by assuring that current incomes do not fall below some crucial level. Second, the policy can try to help assure that poor people break out of poverty when the opportunity arises. The former aspect can be termed protection, while the second is promotion. ${ }^{19}$ The perfect targeting case is clearly good for protection, but bad for promotion. The basic income idea is good for promotion but is unresponsive to shocks and so offers less protection. Any imaginable targeted program will face a trade-off between these two objectives.

\footnotetext{
${ }^{17}$ This has been called many things including a "poll transfer," "guaranteed income," "citizenship income" and an "unmodified social dividend."

${ }^{18}$ See Meade (1972), Atkinson and Sutherland (1989), Atkinson (1995), Raventós (2007) and Bardhan (2011).

${ }^{19}$ Applying a useful distinction made by Drèze and Sen (1989) and formalized by Ravallion et al., (1995).
} 
How do we determine the BWR is in practice? Here we only attempt to estimate the mean BWR $(-\beta)$, so we re-write (1) as:

$$
T_{i}=\alpha+\beta Y_{i}^{*}+\varepsilon_{i}
$$

Here $\varepsilon_{i}=\left(\beta_{i}-\beta\right) Y_{i}^{*}+\alpha_{i}-\alpha$ and $E\left(\varepsilon_{i} \mid Y_{i}^{*}\right)=0$ by construction. We cannot estimate (2) as a linear regression since $Y_{i}^{*}$ is unobserved. Common practice in benefit incidence studies is (in effect) to replace $Y_{i}^{*}$ by actual (observed) income net of transfers received from the program. ${ }^{20}$ Mean transfer receipts (or tax payments) are then tabulated against net income. A linear "benchmark model" for estimating the BWR consistent with this practice would then entail running an ordinary least squares (OLS) regression, giving transfer receipts conditional on income net of transfers:

$$
T_{i}=\alpha+\beta\left(Y_{i}-T_{i}\right)+\mu_{i}
$$

Here $Y_{i}$ denotes the observed (survey-based) total income. Equation (3) can be interpreted as the linear regression corresponding to the long-standard non-behavioral method of assessing benefit incidence, as described in the introduction.

Equation (3) can be derived from (2) by postulating a behavioral model for incomes. Past non-behavioral benefit incidence studies for developed countries have argued that the rigidity of working hours makes an incentive effect on labor supply unlikely (see, for example, Kakwani, 1986). By similar logic, measurement errors are not presumably of much concern. As we have noted, this fixed-income assumption is questionable with reference to all income sources, though defensible for some sources. This is a clue for identification. In particular, we postulate two components of income net of transfers: Component 1 comprises those income sources that are unaffected by the program and measured accurately, while Component 2 comprises sources that are influenced by behavioral responses to the transfers and are also measured with error. Candidates for Component 1 are formal (regular salaried) income and property income while Component 2 includes earnings from casual work (not regular salaried work), self-employment income, and private transfers.

\footnotetext{
20 The examples, of which there are many, include Kakwani (1986), Atkinson and Sutherland (1989), Sahn and Younger (2003), Bourguignon et al. (2003), Goni et al. (2011), Ben-Shalom et al. (2012) and Lustig et al. (2014). Reviews of studies of benefit incidence in developing countries can be found in van de Walle (1998) and Demery (2003).
} 
Assuming that transfer receipts displace Component 2 linearly at a rate $\pi_{i}$ for household $i$ and allowing for classical measurement errors we can write:

$$
Y_{i}=Y_{i}^{*}+\left(1-\pi_{i}\right) T_{i}+v_{i}\left(0 \leq \pi_{i} \leq 1\right)
$$

where $E\left(v_{i} \mid T_{i}, Y_{i}^{*}\right)=0 . .^{21}$ If there is no (income-relevant) behavioral response to the program then $\pi_{i}=0$ for all $i$, in which case income net of transfers $\left(Y_{i}-T_{i}\right)$ is a valid proxy for $Y_{i}^{*}$ (with only measurement error to worry about). At the other extreme, when $\pi_{i}=1$, extra transfer income displaces other income one-for-one, i.e., there is no impact of the program. Between these extremes, we can expect that income net of transfer receipts will be affected by the program through its incentive effects such as on labor supply decisions.

With the behavioral model in (4) it can be seen that the estimable model in (3) is related to the theoretical model in (2) through the properties of the error term, which takes the form:

$$
\mu_{i}=\beta \pi_{i} T_{i}-\beta v_{i}+\varepsilon_{i}
$$

Given this structure to the error term we can readily derive the following expression for the asymptotic value of the OLS regression coefficient:

$$
\operatorname{Plim} \hat{\beta}_{O L S}=\beta\left\lfloor 1-\gamma+\frac{\operatorname{Cov}\left(\pi_{i} T_{i}, Y_{i}-T_{i}\right)}{\operatorname{Var}\left(Y_{i}-T_{i}\right)}\right\rfloor+\frac{\operatorname{Cov}\left(\varepsilon_{i}, Y_{i}-T_{i}\right)}{\operatorname{Var}\left(Y_{i}-T_{i}\right)}
$$

where $\gamma \equiv \operatorname{Var}\left(v_{i}\right) / \operatorname{Var}\left(Y_{i}-T_{i}\right)$ is the share of the variance in observed net incomes accountable to measurement errors. As equation (6) makes clear, the usual attenuation bias due to measurement errors is augmented by two further sources of bias. First, there is an incentive effect stemming from any correlation between net income and the effect of transfer receipts on other income. Second, there is a source of bias stemming from correlated incidence heterogeneity - specifically a non-zero correlation between the differences in BWRs across households and their net incomes. ${ }^{22}$ Let us examine these biases in turn.

If the incentive effect is stronger at higher incomes $\left(\operatorname{Cov}\left(\pi_{i} T_{i}, Y_{i}-T_{i}\right)>0\right)$ then it will work to offset the attenuation bias. A sufficiently positive correlation between the incentive

\footnotetext{
${ }^{21}$ We confine attention to classical measurement errors. More generally, transfer receipts could also be measured with error and this error could well be correlated with the measurement error in incomes, which could either offset the attenuation bias or magnify it (depending on the sign of this correlation).

${ }^{22}$ This is an example of what sometimes called "correlated random effects" in the literature. In the context of impact evaluation this is essentially what Heckman et al.(2006) call "essential heterogeneity."
} 
effect and income would eliminate the bias due to measurement error (although this would be something of a fluke event). A negative correlation would strengthen the attenuation bias. On $a$ priori grounds it is unclear what direction of bias is most likely due to incentive effects.

There is a stronger a priori case for signing the second source of bias (on top of that due to measurement errors). If the observable data are consistent with the aim of the program to reduce poverty then it would be reasonable to assume that this is also true of the unobservables; specifically, that the latent variation in the scheme's BWR will be such that poorer households end up with larger transfers, i.e., $\operatorname{Cov}\left(\varepsilon_{i}, Y_{i}-T_{i}\right)<0$. We can call this the assumption of latent pro-poor incidence. Under this assumption, OLS will over-estimate the BWR in the absence of either income measurement errors or incentive effects. More generally, the net bias is unclear.

A special case lends itself to a straightforward interpretation. Suppose that both the BWR and the incentive parameter are constant across households. Then it is readily verified that: ${ }^{23}$

$$
\operatorname{Plim} \hat{\beta}_{\text {OLS }}=\frac{\beta(1-\gamma)}{1-\beta \pi}
$$

For $\beta<0$ and $\pi>0$ it can be seen that OLS will be biased downwards for the BWR, and this holds even without income measurement errors. The two sources of bias work in the same direction leading OLS to underestimate the BWR.

How might the bias be removed? Some common methods using panel data would be illadvised. For example, notice that the structure of the error term in equation (5) does not suggest that a household fixed effect specification would provide a good estimate since the sources of bias are not constant over time. Indeed, one may well expect an even lower signal-to-noise ratio in such an estimator $\left(\operatorname{Var}\left(\Delta v_{i}\right) / \operatorname{Var}\left(\Delta Y_{i}-\Delta T_{i}\right)>\gamma\right)$ and (hence) greater bias than for OLS. ${ }^{24}$

We will instead use an Instrumental Variables (IV) estimator under our assumption that both the incentive effects and the measurement errors are confined to Component 2 of income. Recall that Component 1 is assumed to be both measured accurately and not prone to incentive effects of the program. If incentive effects and income measurement errors are the only source of bias (in other words, there is no heterogeneity in the BWR) then these income sources can be

\footnotetext{
${ }^{23}$ To derive this expression note first that the probability limit of the OLS regression coefficient ( $\hat{\beta}_{\text {OLS }}$ ) is (as usual) $\beta+\operatorname{Cov}\left(\mu_{i}, Y_{i}-T_{i}\right) / \operatorname{Var}\left(Y_{i}-T_{i}\right)$. The second term can be written as $\beta\left(\pi \hat{\beta}_{O L S}-\gamma\right)$. On solving we obtain equation (7).

${ }^{24}$ For further discussion of this source of bias in fixed-effects estimators see Deaton (1995).
} 
used as the IVs for income net of transfers. It is important that Component 1 income is a good predictor of total income to avoid the weak instruments problem; if the IVs are weak then there is no reason to suppose that the IV estimator is less biased than OLS. (Section 3 comments on the validity of our identification strategy in the Chinese context.)

Correlated incidence heterogeneity can invalidate the IVs. If the BWR varies systematically, then the IVs based on Component 1 are likely to be correlated with the error term through their non-zero covariance with the $\varepsilon_{i}$ 's. To help address this concern, we exploit our panel data by using the lagged values of Component 1 income sources as the IVs.

However, while this will go some way toward reducing the bias, we acknowledge that (as in other applications using lagged values as IVs) positive serial correlation in incomes can jeopardize this identification strategy. This could arise from common effects of preference parameters across time. However, under the assumption above of latent pro-poor incidence, the unobserved differences in transfer receipts will tend to favor poor people. Then we can expect that our IVs are negatively correlated with the error term. Having removed the bias due to incentive effects and measurement errors (under our assumptions), the true value of the mean $\operatorname{BWR}(-\beta)$ will then be lower than our IV estimate. ${ }^{25}$

By bounding the bias in the IV estimator under our assumption of latent pro-poor incidence we will still be able to draw a robust policy implication in our application to follow.

\section{Background and data}

Economic transformation has come with a dramatic change in the nature of social protection in China, which has switched from employer-based security arrangements (the socalled "iron rice bowl") to an increasing role of government at all levels. This has been a policy response to fundamental changes in the urban labor markets, themselves stemming from policy changes (World Bank, 2007, 2010; Ravallion, 2014b). A new form of open unemploymentfound in many other economies but new to China-emerged in urban China in the late $20^{\text {th }}$ Century, in the wake of retrenchments of workers in un-profitable state-owned enterprises since the mid-1990s. Not surprisingly, those least able to work, including the disabled or unhealthy, tended to be the first to go. Having previously been protected by their work units, they were now

\footnotetext{
${ }^{25}$ Note that (as usual) $\operatorname{Plim} \hat{\beta}_{I V}=\beta+\operatorname{Cov}\left(Z_{i}, \mu_{i}\right) / \operatorname{Cov}\left(Z_{i}, Y_{i}-T_{i}\right)$ where $Z$ is the IV.
} 
exposed to market forces. Using a 2000 survey, Appleton et al. (2002) found persistently high unemployment amongst retrenched workers, who tended to have fewer skills, less education, poorer health, and to be women and middle-aged. Less secure, less regular forms of part-time work have also become more common in urban China (Solinger, 2002; Park and Cai, 2011).

The Dibao program is China's main social policy response. The Dibao program introduced a new concept of the social safety net to China. It is the first social transfer program and the first national social policy to be disconnected from the recipient's place of employment, and the first program to not involve co-payments from employers. ${ }^{26}$ Prior to Dibao, urban China's social protection programs focused on the "three-without" people, namely those without savings, without an ability to work, and without family members for support. Even then coverage was limited. While there is no other national program of targeted transfers, China does have a progressive income tax. However, this appears to have little effective relevance in this context as it only comes into play at relatively high incomes from formal sources. Negligible income taxes are paid by poor and even middle-income people.

Not unlike most past policy debates on antipoverty policy in England, Europe and North America (as discussed in the Introduction), there is little or no evidence on the actual incentive effects in practice of this major new social program. The main problem identified in past research on the program is seemingly weak coverage of the eligible participants rather than leakage to ineligible participants (Chen et al., 2008; Gao et al., 2009). However, this assessment ignores incentive effects and measurement errors. Coverage may be weak but expanding coverage would be ill-advised if in fact the program is creating a poverty trap.

While our assumption that Component 1 income sources exist can be questioned in principle - in that formal salaried income might be forgone or hidden to gain access to welfare benefits - the assumption appears to be a reasonable one in the context of China's Dibao program. The validation of reported incomes is relatively easy for likely Component 1 sources. Based on our observations in the field, formal sector earnings appear to be well known locally, and so not easily hidden. Applicants for Dibao are required to provide a formal salary statement from their employer if one exists as well as a statement from the Bank. (Formal salaries are typically deposited directly to the worker's Bank account.) The Dibao officer and program assistant from the local resident committee interview the applicant and are charged with double

26 This is in contrast to Xia-gang, which provides a layoff subsidy as a form of unemployment insurance. 
checking their income. This review process is repeated every three to six months as long as the person stays in the program. In principle a worker might quit a formal sector job to qualify for Dibao. But then the income loss would be far greater than potential Dibao receipts. This was corroborated in our interviews during the field work, which suggested that it is quite unlikely that anyone would be willing to give up a formal-sector job in order to access Dibao. There would also be a considerable loss of status in the community. A formal sector job is held with pride. Also, traditional Chinese values discourage people from taking "free money" when one is able to work.

In summary, while we cannot rule out measurement errors and incentive effects through the income sources we identify as Component 1, these do appear likely to be serious concerns in this context. However, we caution that whether our assumption about Component 1 incomes is plausible in other contexts is an open question.

The data structure we devised for studying this program is somewhat unusual. Similarly to other researchers, we could not obtain access to the complete micro data for China collected by the National Bureau of Statistics (NBS) Under Chinese law NBS cannot provide those data. So we could not estimate a censored regression model (such as a Tobit model) of DB receipts on a sample of the entire urban population (or even selected provinces). However, with NBS's cooperation, we could obtain a sub-sample of actual and potential DB participants for selected cities and follow up this sample for re-interviewing.

As our sample for estimating the BWR for the DB program we use actual participants or likely participants for seven cities, as given in Table 1, which gives sample sizes and participation rates by city. The seven cities were chosen to span China's main geographic areas as well as representing a range of city sizes. In terms of growth rates, they also span a wide range. In identifying actual or likely DB participants we are explicitly excluding the vast majority of urban Chinese for whom participation in the DB program is unimaginable as they have incomes well beyond the DB poverty lines, and are very unlikely to ever need the program. On a priori grounds, DB receipts and (of course) the BWR can be set to zero for them.

We drew our sample from the 2007 Urban Household Short Survey (UHSS) by China's NBS. The UHSS is an unusual survey. It is the first step in constructing the sample for the regular Urban Household Survey (UHS), which has a much longer questionnaire, but much smaller sample. The big advantage of the UHSS here is that its sample size allows us to capture 
a significant number of DB participants, to be interviewed further. Also, while the UHSS is a relatively short survey, it allows us to measure a fairly wide range of household characteristics including income by source. The UHSS is unlikely to give as accurate a measure of total income as obtained from surveys that use more detailed questions on income by source, such as NBS's smaller UHS. However, the latter survey includes too few DB households for our purposes. Chen et al. (2006) describe the survey data in greater detail.

The population with which we are concerned is all actual or "potential" participants in a targeted antipoverty program. We can readily identify actual participants (denoted $D=1$ ) but potential participants are more difficult. We used a model of participation conditional on covariates $X$ to identify non-participants with a probability of participation greater than some critical value, $P\left(D_{i}=1 \mid X_{i}\right)>P^{\mathrm{min}}$. The sample we use is thus all those households who are actual participants in DB in the base year plus a sample of the same size comprising those with the highest predicted probability of participation based on their covariates in that survey round.

We drew samples of all 1,040 Dibao participant households and 1,029 "high propensity" non-participants from the 2007 UHSS for seven cities. The high propensity households were those with the highest propensity scores (predicted probabilities) for DB participation in the UHSS, based on probit using a large number of explanatory variables; this was essentially the same probit reported in Chen et al. (2006). These 2069 households were resurveyed in 2009 and 2010. The surveys were done by the Urban Household Survey Division of the NBS. In addition we had numerous informal, open-ended, interviews in 2007, 2009 and 2010 with DB officials (central and local) and DB households in Beijing, Chongqing, Tianshui and Wuhan.

The UHSS measured household income from responses to a series of questions on income by broad categories (formal salary income, business income, casual work, selfemployment, private transfers and DB). Measurement errors in the reported incomes must be anticipated although more so for some components than others. It should also be noted that survey-based incomes may differ from income at the time of assignment for DB eligibility. Checks on the latter are done by local authorities/neighborhood committees and there is also a community appeals process. And it should be noted that there is more than one way to assess "income." For example, there are differences in the time period deemed relevant (current income vs. longer-term income). Possibly DB officials use a different time period to the survey. 
Table 2 summarizes the overall participation rates and the entry and exit rates for the combined sample of actual (2007) participants and the high-propensity participants. There is significant "stickiness" as indicated by the dominant diagonals in these joint distributions. Over the period 2007-10, we find that a greater number of households left the program than joined. This was confirmed by administrative data from MOCA.

Given the low entry rate from the initial sample of likely participants we will also estimate the mean BWR for sub-samples of participants only, defined as those who were found to have participated in at least one survey round.

\section{Estimation results}

The simple OLS coefficient of DB receipts on income net of DB implies a BWR of $6.5 \%$ $(\mathrm{t}=5.4)$ (Table 3). Adding time effects this rises slightly, to $7.2 \%(\mathrm{t}=5.1)$. We also give results for subsamples of DB participants only. The sub-sample gives similar results to the full sample. So instead of a 100\% marginal tax rate these calculations suggest a rate of only around $7 \%$. However, this may well be a large under-estimate, as discussed in Section 2.

Table 3 also gives results for household fixed-effects regressions of DB receipts on income net of DB using our three-year panel. This gives an even lower BWR of $3.1 \%(\mathrm{t}=-3.9)$ using all households in sample and 4.9\% ( $\mathrm{t}=-2.3)$ using only those households who receiving DB income at least once (Table 3). However, as discussed in Section 2, we expect that greater noise in the changes over time may well be imparting a downward bias in the fixed effects estimator.

The IV results are in Table 4. Recall that the IVs are lagged regular salaried income and lagged property income. These were very significant predictors for net income in the first stage regressions. ${ }^{27}$ The IV estimator gives an appreciable higher BWR of 12-14\%, roughly double the OLS estimate. As noted in Section 2, we cannot rule out remaining bias due to correlated incidence heterogeneity, stemming from a positive serial correlation in incomes and latent heterogeneity in the BWRs. Under our assumption of a latent pro-poor incidence (consistent with its objective of reducing poverty), the true value of the mean BWR will be no greater than our IV estimate. Although the BWR implied by our IV estimator is about twice the OLS estimate, it is still appreciably lower than the value of $100 \%$ implied by the scheme's design.

\footnotetext{
${ }^{27}$ On the full sample, the F-statistic for the regression of income net of DB on the two IVs was 80.61, with prob. $<0.00005$; for the participant sub-sample it was 38.03 with prob. $<0.00005$.
} 
Table 5 gives both estimates by city. (We only give results for the whole sample given the sample sizes.) The IV estimate of the BWR exceeds OLS for all except Pingliang. We see a marked variation across cities with the IV estimates ranging from $6 \%$ to $27 \%$. For the IV estimates (but not OLS) there is a positive correlation between the BWR and mean income (from Table 1); the correlation coefficient is 0.67 which is significant at the $10 \%$ level. Of course, with only seven cities one should be cautious here, but it is at least suggestive that richer cities tend to put higher weight on protection. Naturally richer cities have greater fiscal resources and this influences program implementation; in particular, Ravallion (2009a) shows that richer cities of China tend to have more generous DB lines.

It is not, however, clear why the balance shift from promotion toward protection (in the form of a higher BWR) in richer cities. (A similar pattern has been found in the cross-country evidence on spending on social insurance and also with inter-temporal comparisons for the US; see Krueger and Meyer, 2002.) One possibility is that richer cities have more professional and capable local officials, who are less prone to the type of "participant capture" that brings down the BWR.

We tested a number of variations. In one we allowed for other sources of heterogeneity in DB transfer receipts by adding a quadratic function of the propensity scores for DB participation by regressing on a broad set of covariates (similarly to the covariates used in the probits reported in Chen et al., 2006). The mean BWR was slightly lower (in absolute value), though still significantly different from zero. We also tested for lagged income effects by adding the lagged net income as a regressor; we give these results for the IV estimator in Table 4. There is a small lagged effect, but the overall results are similar.

As an aside, given these findings, it is of obvious interest to ask how much the program helped in protecting China's poor from the Global Financial Crisis of 2009. Some straightforward simulations are suggestive. The top panel of Table 6 gives the actual transitions above and below a fixed poverty line that we set at 1.5 times the local DB line. The second panel gives the results when we set all DB payments to zero in 2009, while the third panel gives the results when we set DB receipts in 2009 to their 2007 values. We see that, despite the low BWR, DB payments still protected some households from falling into poverty during the crisis. Only 32 households fell into poverty (by this definition) between 2007 and 2009. In the absence of DB payments the number would have been $225-11 \%$ of the sample. However, in assessing the 
responsiveness of the scheme to shocks the changes in DB payments are more relevant. Then we see that program had less impact, with 71 households falling into poverty without the changes in DB payments, as compared to the observed count of 32 (Table 5, lower panel).

\section{Implications}

We focus on two implications. The first concerns standard (non-behavioral) benefit incidence calculations while the second relates to reforms of the Dibao program.

Implications for benefit incidence: A strand of the policy-oriented literature has ignored or downplayed behavioral responses, sometimes arguing that their non-behavioral incidence calculations are a good approximation (though it has rarely been clear why). ${ }^{28}$ Our results illustrate the potential for a large discrepancy between the BWR implied by a scheme's formal rules and its actual implementation. Simulation methods based on nominal rates and rules could be especially deceptive in settings in which there is considerable local discretion in implementation.

A higher BWR for a given aggregate transfer and given distribution of income in the absence of the program clearly implies larger transfers to the poorest households. To gauge how much difference this makes, consider the average transfer payment to someone at zero income in the absence of the program $\left(E\left(T \mid Y^{*}=0\right)\right)$ - the intercept in the benefit incidence function. It is readily verified that the derivative of this expected value with respect to the BWR is simply the overall mean income in the absence of the program. ${ }^{29}$ This is not, of course, data, but a fair approximation is overall mean income, which is 975 Yuan per month for urban China (Table 1). Thus an increase in the estimated BWR of 0.08 (implied by the switch to our IV estimate for the "anytime" participants) yields an increase in the mean transfer payment to someone at zero income of 78 Yuan per month, over three-quarters of the mean DB payment. This is clearly a sizeable impact, leading us to question past claims in the literature that using net income (ignoring incentive effects) provides a good approximation.

\footnotetext{
${ }^{28}$ For example, Sahn and Younger, 2003, p.29) claim that the non-behavioral (fixed-income) method provides a "satisfactory short-cut for the study of a policy's distributional impact." Also see Lustig et al. (2014).

${ }^{29}$ To verify this, note first that $\bar{T}=\left(\alpha+\beta \bar{Y}^{*}\right) P$ where $P$ is the overall participation rate. Then $E\left(T \mid Y^{*}=0\right)=(\bar{T} / P)-\beta \bar{Y}^{*}$ as claimed.
} 
Reforming the program: The BWRs found in practice have spanned a wide range from negative values to $100 \% .{ }^{30}$ However, a strand of the literature has attempted to identify optimal BWRs. Intuitively, as long as both protection and promotion are valued, the optimal benefit withdrawal rate on a scheme such as Dibao is unlikely to be unity, but nor is it likely to be close to zero. Can the range be narrowed further?

Three papers in the literature are especially relevant (all influenced by the seminal paper by Mirrlees, 1971). First, Kanbur, Keen and Tuomala (1994) study the optimal design of a stylized program aiming to minimize a measure of poverty when there is an incentive effect on labor supply, and they come to the conclusion that the optimal BWR would be around $60-70 \% .^{31}$ By contrast, our preferred IV estimates suggest that the BWR for DB is 12-14\%. Even in the highest-income city in our study, Beijing, the rate is $27 \%$. And, under our assumption of latent pro-poor incidence, these BWRs overestimate the true values of the mean BWR.

Second, Saez (2002) simulates optimal transfers for a range of parameter combinations for a utilitarian social welfare function (rather than a poverty measure as in Kanbur et al). Under the combinations Saez considers plausible and for a moderate to high aversion to inequality the implied marginal tax rates on the poor are still higher than we find for the DB program.

Third, the same conclusion is reached based on the results of Kanbur and Tuomala (2011) who consider various social welfare objectives, including "Rawlsian" maximin, a poverty reduction objective and "charitable conservatism," whereby one puts positive weight on the nonpoor but is indifferent to inequality amongst them. Under their chosen parameterizations, all three objective functions imply marginal tax rates on the poorest half or so of the population that are appreciably higher than we find for the DB program.

We cannot, of course, be certain about the relevance of these studies to the present setting. However, there is little else to guide us. To the extent that these results from the optimal taxation literature can be considered relevant to China, our findings suggest that the BWR for DB is lower than the values for comparable tax parameters that emerge from that literature. Incentive arguments do not suggest that the DB program should be perfectly targeted as long as promotion is valued alongside protection. However, our results suggest that DB payments respond little to changes in household income from other sources. While such a low BWR makes

30 See Moffitt (2002) and Maag et al (2012) with reference to US programs.

31 Naturally such calculations require functional-form assumptions. Kanbur et al. assume Cobb-Douglas preferences, implying an elasticity of substitution between consumption and leisure of unity. 
it unlikely that the program would provide a serious disincentive for earning extra income, it raises concerns about how well the program reaches the poorest and how well it adapts to changes in household needs. This raises doubts about how well the program is addressing uninsured risk and transient poverty. In short, adverse incentives do not appear to be a problem in this program, but protection from poverty is a concern.

We can make a number of further observations to help understand this finding, including from our field work. While the design of the scheme suggests that the center puts a high weight on protection, it must rely on local implementing agents and the information provided by actual or potential recipients. Like many social spending programs in China and elsewhere, Dibao relies heavily on decentralized implementation. While the national and provincial governments provide guidelines and co-financing (to all except the well-off coastal provinces), the selection of beneficiaries is under municipal control. Each municipality determines its own DB line and finances the transfers in part at least from local resources. Claimants must apply to the local (county or district-level) MOCA office for DB assistance, and they typically do this through their local community committee, which administers the program on a day-to-day basis. There is also a community-level vetting process whereby the names of proposed participants are displayed on local notice boards and community members are encouraged to identify any undeserving applicants. However, there is still scope for participants to hide some sources of income, such as transfers from friends or relatives.

Our qualitative observations from our field work suggest that local agents actively "smooth" DB payments and participation. For example, we were told by local MOCA officials that they often allow DB benefits to continue for some period after a participating family finds extra work. Local officials are clearly aware of the incentive problem, and expressed concerns both DB participants becoming too dependent on transfers from the program, with too little incentive to work. ${ }^{32}$ There appears to be ample scope for local discretion in implementation so as to provide enhanced work incentives.

The implicit preferences of local officials appear to be closer to a promotion objective than the protection objective of the central government. It is seen as unacceptable at local level to cut DB payments to poor people one knows (possibly quite well) when their income rises. Resistance naturally comes from participants too. When interacting with local officials over a

\footnotetext{
${ }^{32}$ Hammond (2009, p.185) also notes that local officials expressed concerns about dependency on DB.
} 
sustained period there is scope for "participant capture." A social bond forms between the two parties, which lowers the BWR in practice. Our field work also suggested that there can be frictions in the entry of new participants, such as due to costs of finding and obtaining information and checking. Stigma effects cannot be ruled out either.

There are also insights into the findings and implications of some past research on the Dibao program. The program has been found to be quite good at avoiding leakage to the nonpoor. DB recipients are more likely to be poor and unemployed (Wang, 2007; Chen et al., 2008; Gustafsson and Deng, 2011). Coverage of the poor is clearly the bigger problem. The authorities know this as the "ought to protect, not protecting" (yingbao weibao) problem (Hammond, 2009). Despite the program's aims, it is clearly not reaching the majority of those households with a reported income (net of DB) below the DB line (Chen et al., 2008; Chen and Ravallion, 2011). Gao et al. (2009) estimate that the program only reaches half of its intended beneficiaries. Chen et al. (2008) estimate that the program is only covering about one-eighth of the aggregate income gap relative to the DB lines. The benefit levels for retrenched workers are clearly well below their prior wages. It is the program's weak coverage and low benefit levels the scheme's impact on poverty is modest (Ravallion, 2009b).

This pattern of restricted coverage identified in the literature on DB may well be a sensible response by the authorities to the incentive concerns about the program's design. If indeed the program was creating a poverty trap, then rationing access would be the only way of dealing with the problem without more fundamental reforms in the program's design. Absent such reforms, one would be loath to expand coverage to all who claim eligibility.

While we agree that one should be concerned about expanding coverage if the program is generating a poverty trap, our results do not suggest that this is an important concern in practice. Expanded coverage would probably not entail significant efficiency costs due to the program's incentive effects. The greater concern would appear to be whether the scheme is adjusting flexibly enough to household income shocks to provide adequate protection. That would call for design changes to assure a higher BWR than appears to be the case at present. A combination of such design changes and expanded coverage would be needed to assure greater poverty impact. 


\section{Conclusions}

In assessing whether China's Dibao program has created a poverty trap, we have offered a new applicable approach to estimating average benefit incidence that can be implemented with essentially the same data as prevailing methods of non-behavioral benefit-incidence analysis, but without ignoring incentive effects and measurement errors. The point of departure from past work is that we focus directly on a key policy parameter, namely the benefit withdrawal rate (or marginal tax rate). Our key assumption is that incentive effects and classical measurement errors only impact certain lagged income components but that these still have predictive power for isolating exogenous variation in total income net of transfers/taxes. This justifies an instrumental variables estimator for the mean benefit withdrawal rate.

Our assumption that lagged formal income sources are measured accurately and unlikely to be affected by incentives is more plausible than the fixed-income assumption, but it is not beyond question. While we have argued that the assumption is plausible in our setting, we have also pointed to a source of bias that we cannot easily rule out, stemming from correlated differences in the program's idiosyncratic benefit withdrawal rates. Correlated incidence heterogeneity casts doubt on the exclusion restriction for our instrumental variables estimator. Nonetheless, we have argued that, as long as this source of heterogeneity reflects latent pro-poor targeting (consistent with the observed data) then we can interpret our preferred estimate of the mean benefit withdrawal rate as an upper bound to the true value.

To implement our approach, we have used a specially designed and commissioned survey to study what is probably the largest cash transfer programs in the world (in terms of coverage), namely China's Dibao program. Our results suggest a sizeable bias in the benefit incidence picture that is implied by either the formal rules or the usual statistical practice of calculating conditional means at different net incomes. In the present application, our estimated mean benefit withdrawal rate is much lower than the formal rules suggest, yet about double that implied by the standard statistical approach.

By focusing on the key parameter for policy design, we can also offer some insights for policy reform in the light of the literature on optimal taxation. The central government's design for Dibao aims to use means-tested transfers to assure that no registered urban resident has an income below a stipulated "Dibao poverty line." In theory this is ideal for protection but bad for 
promotion given that it imposes a 100\% marginal tax rate on poor participants - a poverty trap. However, we find no sign of this in the data. Indeed, the benefit withdrawal rate appears to be quite low, at least when compared to the range of values suggested by optimal tax studies. Incentives for "promotion" appear to be strong, but performance in "protection" seems weak. We have argued that the reason may be found in local implementation practices. Local agents implicitly put a far higher weight on promotion than implied by the central government's design for the scheme. There is heterogeneity in this respect, with an indication in the data that richer cities tend to put higher weight on protection. Participant capture appears to be a greater problem in poorer cities. One possible explanation is that richer cities have more professional local administrators, less prone to participant capture.

Our key policy conclusion is that the Dibao program is unlikely to provide a strong disincentive for earning extra income among participants. Incentive effects appear to be more serious than presumed by standard non-behavioral incidence analysis but still much less severe than basic incentive theory would suggest given the program's design on paper. Indeed, our findings suggest that reforms to the program should consider a higher benefit withdrawal rate in local implementation, alongside expanded coverage.

Of course, this is just one application of our proposed method. We cannot guarantee that the method will work well in other settings. Importantly, it must be plausible that at least some significant income sources can be treated as exogenous and measured accurately. Otherwise, there is a danger of a weak-instruments problem, whereby a low correlation between the instruments and total income artificially inflates the estimated mean benefit withdrawal rate. While the method is defensible in our setting, it is remains an open question whether it will be applicable elsewhere. 
Table 1: 2007 UHSS sample for seven cities and 2007 summary data

\begin{tabular}{lcccccc}
\hline City & $\begin{array}{c}\text { Sample } \\
\text { size }\end{array}$ & $\begin{array}{c}\text { Of which DB } \\
\text { households }\end{array}$ & $\begin{array}{c}\text { \% of DB } \\
\text { households }\end{array}$ & $\begin{array}{c}\text { DB spending } \\
\text { per capita of } \\
\text { participants } \\
\text { (Yuan per } \\
\text { month) }\end{array}$ & $\begin{array}{c}\text { DB line } \\
\text { (Yuan per } \\
\text { month) }\end{array}$ & $\begin{array}{c}\text { Mean } \\
\text { income } \\
\text { (Yuan per } \\
\text { person per } \\
\text { month) }\end{array}$ \\
\hline Beijing & 33286 & 352 & 1.06 & 269.29 & 327.78 & 1835.00 \\
Shenyang & 12080 & 207 & 1.71 & 144.24 & 244.69 & 1129.73 \\
Jinan & 8000 & 195 & 2.44 & 132.81 & 249.09 & 1022.53 \\
Wuhan & 4689 & 205 & 4.37 & 116.81 & 219.38 & 1054.30 \\
Chongqing & 14324 & 1128 & 7.87 & 104.26 & 178.33 & 1021.73 \\
Tianshui & 912 & 134 & 14.69 & 102.79 & 148.00 & 555.50 \\
Pingliang & 820 & 221 & 26.95 & 103.89 & 138.00 & 531.44 \\
\hline Urban China & 493975 & 16365 & 3.31 & 101.74 & 182.40 & 974.67 \\
\hline
\end{tabular}

Note: DB spending and poverty line data from MOCA. The last row gives aggregates for all of urban China, not just the seven cities listed.

Table 2: Exit and entry from the Dibao program 2007-2010

(a) 2007 as the base year

\begin{tabular}{rr|cccccc}
\hline & & \multicolumn{2}{|c}{ DB in 2009? } & \multicolumn{4}{c}{ DB in 2010? } \\
& & No & Yes & Total & No & Yes & Total \\
\hline DB in & No & 931 & 98 & 1,029 & 820 & 99 & 919 \\
$2007 ?$ & Yes & 216 & 824 & 1,040 & 272 & 675 & 947 \\
\hline & Total & 1,147 & 922 & 2,069 & 1,092 & 774 & 1,866 \\
\hline
\end{tabular}

(b) 2009 as the base year

\begin{tabular}{rr|ccc}
\hline & & \multicolumn{3}{|c}{ DB in 2010? } \\
& & No & Yes & Total \\
\hline DB in & No & 959 & 59 & 1,018 \\
$2009 ?$ & Yes & 133 & 715 & 848 \\
\hline & Total & 1,092 & 774 & 1,866 \\
\hline
\end{tabular}




\section{Table 3: Estimated benefit withdrawal rates using OLS}

\begin{tabular}{lcc}
\hline & Whole sample & Participants only \\
\hline Simple OLS regression & $-0.065^{* * *}$ & $-0.065^{* * *}$ \\
& $(0.012)$ & $(0.023)$ \\
With year effects & $-0.072 * * *$ & $-0.067 * * *$ \\
& $(0.014)$ & $(0.025)$ \\
With both year and household & $-0.031^{* * *}$ & $-0.049 * * *$ \\
fixed effects & $(0.008)$ & $(0.021)$
\end{tabular}

Note: Regression coefficient of DB receipts on income net of DB. Standard errors in parentheses. ***: Significant at $<1 \%$. "Participants" are defined as those who participated at least once.

Table 4: Instrumental variables regressions using lagged exogenous income sources as IVs

\begin{tabular}{lcccc}
\hline & \multicolumn{2}{c}{ Whole sample } & \multicolumn{2}{c}{ Participants only } \\
\hline Income net of DB & $-0.1205^{* * *}$ & $-0.1179 * * *$ & $-0.1446 * * *$ & $-0.1377 * * *$ \\
& $(0.009)$ & $(0.009)$ & $(0.020)$ & $(0.019)$ \\
Lagged income net & n.a. & -0.0022 & n.a. & $-0.0047 * * *$ \\
of DB & & $(0.010)$ & & $(0.001)$ \\
\hline No. obs. & 3935 & 3935 & 2245 & 2245 \\
F & 178.91 & 95.69 & 55.73 & 84.46 \\
(prob.) & $(0.000)$ & $(0.000)$ & $(0.000)$ & $(0.000)$ \\
\hline
\end{tabular}

Note: BWR estimated by regressing DB payments on income net of DB using lagged formal salary and lagged property income as the IVs. Robust standard errors in parentheses.***: Significant at $<1 \%$. 
Table 5: Estimated benefit withdrawal rates by city

\begin{tabular}{lccc}
\hline $\begin{array}{l}\text { Regression coefficient of DB } \\
\text { receipts on income net of DB }\end{array}$ & $\mathrm{n}$ & OLS & IV \\
\hline \multirow{2}{*}{ Beijing } & 1242 & $-0.0574 * * *$ & $-0.2727^{* * *}$ \\
& & $(0.0213)$ & $(0.045)$ \\
Shenyang & 918 & $-0.0955^{* * *}$ & $-0.1817^{* * *}$ \\
& & $(0.009)$ & $(0.024)$ \\
Jinan & 856 & $-0.0718^{* * *}$ & $-0.0846^{* * *}$ \\
& & $(0.011)$ & $(0.029)$ \\
Wuhan & 846 & $-0.0885^{* * *}$ & $-0.1438^{* * *}$ \\
& & $(0.008)$ & $(0.028)$ \\
Chongqing & 1187 & $-0.0460^{* * *}$ & $-0.0633^{* *}$ \\
& & $(0.004)$ & $(0.030)$ \\
Tianshui & 480 & $-0.0444 * * *$ & $-0.1535^{* * *}$ \\
& & $(0.016)$ & $(0.056)$ \\
Pingliang & 475 & $-0.1227^{* * *}$ & $-0.1073^{* *}$ \\
& & $(0.018)$ & $(0.045)$ \\
\hline
\end{tabular}

Note: Whole sample. BWR estimated by regressing DB payments on income net of DB. IV estimates use lagged formal salary and lagged property income as the IVs. Robust standard errors in parentheses. ***: significant at 1\%; $* *$ significant at $5 \% ; *$ : Significant at $<10 \%$.

Table 6: Poverty transitions with and without the Dibao program

\begin{tabular}{cccccccc}
\hline & \multicolumn{2}{c}{ Actual transitions } & \multicolumn{2}{c}{ Simulated with } & \multicolumn{2}{c}{$\begin{array}{c}\text { Simulated with } \Delta \\
\mathrm{DB}=0 \text { in } 2009\end{array}$} \\
& $\begin{array}{c}\text { Above } \\
\text { line }\end{array}$ & $\begin{array}{c}\text { Below } \\
\text { line }\end{array}$ & $\begin{array}{c}\text { Above } \\
\text { line }\end{array}$ & $\begin{array}{c}\text { Below } \\
\text { line }\end{array}$ & $\begin{array}{c}\text { Above } \\
\text { line }\end{array}$ & $\begin{array}{c}\text { Below } \\
\text { line }\end{array}$ \\
\hline 2007 & $\begin{array}{c}\text { Above } \\
\text { line } \\
\text { Below } \\
\text { line }\end{array}$ & 1944 & 32 & 1751 & 225 & 1905 & 71 \\
& 84 & 9 & 52 & 41 & 63 & 30 \\
\hline
\end{tabular}

Note: The cut-off line is set at 1.5 times the local DB line. 


\section{References}

Appleton, Simon, John Knight, Lina Song, Qingjie Xia, 2002, "Labor Retrenchment in China: Determinants and Consequences," China Economic Review, 13(2-3): 252-275.

Atkinson, Anthony B., 1995, Public Economics in Action. The Basic Income/Flat Tax Proposal. Oxford: Clarendon Press.

Atkinson, Anthony B., and Holly Sutherland, 1989, "Analysis of a Partial Basic Income Scheme," in A.B. Atkinson (ed.) Poverty and Social Security. Hertfordshire: Harvester Wheatsheaf.

Bardhan, Pranab, 2011, "Challenges for a Minimum Social Democracy in India," Economic and Political Weekly 46(10): 39-43.

Ben-Shalom, Yonatan, Robert Moffitt and John Karl Scholz, 2012, "An Assessment of the Effectiveness of Antipoverty Programs in the United States," in Philip Jefferson (ed.) The Oxford Handbook of the Economics of Poverty, Oxford: Oxford University Press.

Bingley, Paul and Ian Walker, 1997, "The Labour Supply, Unemployment and Participation of Lone Mothers in In-Work Transfer Programmes," Economic Journal 107: 1375-1390.

Bourguignon, Francois, Francisco Ferreira, Phillippe Leite, 2003, "Conditional Cash Transfers, Schooling, and Child Labor: Microsimulating Brazil's Bolsa Escola Program," World Bank Economic Review, 17(2): 229-254.

Bourguignon, Francois and Luiz Pereira Da Silva, 2003, "Introduction," in Francois Bourguignon Francois and Luiz Pereira Da Silva (eds) The Impact of Economic Policies on Poverty and Income Distribution: Evaluation Techniques and Tools. New York: Oxford University Press.

Chen, Shaohua, Martin Ravallion and Youjuan Wang, 2006, "Di Bao: A Guaranteed Minimum Income in China's Cities," Policy Research Working Paper 3805, Washington DC, World Bank. and 2008, "Does the Dibao Program

Guarantee a Minimum Income in China's Cities?" in Public Finance in China: Reform and Growth for a Harmonious Society, edited by Jiwei Lou and Shuilin Wang, Washington DC: World Bank.

Coady, David, Margaret Grosh and John Hoddinott, 2004a, "Targeting Outcomes Redux," 
World Bank Research Observer 19(1): 61-86.

and 2004b, Targeting Transfers in Developing

Countries: Review of Lessons and Experience, Washington DC: World Bank.

Deaton, Angus, 1995, "Data and Econometric Tools for Development Analysis," in J. Behrman and T. N. Srinivasan (eds.), Handbook of Development Economics, North-Holland: Amsterdam and New York, Vol. 3A, pp. 1785-1882.

Demery, Lionel, 2003, “Analyzing the Incidence of Public Spending,” in Francois Bourguignon and Luiz Pereira Da Silva (eds) The Impact of Economic Policies on Poverty and Income Distribution: Evaluation Techniques and Tools. New York: Oxford University Press.

Drèze, Jean and Amartya Sen, 1989, Hunger and Public Action, Oxford: Oxford University Press.

Duckett, Jane and Beatriz Carrillo, 2011, “China’s Changing Welfare Mix: Introducing the Local Perspective," in Beatriz Carrillo and Jane Duckett (eds) China's Changing Welfare Mix: Local Perspective, Oxford: Routledge.

Ellwood, David and Lawrence Summers, 1986, "Poverty in America: Is Welfare the Answer or the Problem?" in Sheldon Danziger and Daniel Weinberg (eds) Fighting Poverty: What Works and What Doesn't. Cambridge: Harvard University Press.

Fan, Elliott, 2010, "Who Benefits from Public Old Age Pensions? Evidence from a Targeted Program," Economic Development and Cultural Change 58(2): 297-322.

Friedman, Milton, 1962, Capital and Freedom, Chicago: University of Chicago Press.

Furniss, Edgar, 1920, The Position of the Laborer in a System of Nationalism. A Study in the Labor Theories of the Later English Mercantilists, Boston and New York: Houghton Mifflin.

Gao, Qin, Garfinkel, Irwin. and Zhai, Fuhua, 2009, “Anti-poverty Effectiveness of the Minimum Living Standard Assistance Policy in Urban China," Review of Income and Wealth 55: 630-655.

Goni, Edwin, Humberto Lopez and Luis Serve, 2011, "Fiscal Redistribution and Income Inequality in Latin America," World Development 39(9): 1558-1569.

Grosh, Margaret, Carlo del Ninno, Emil Tesliuc and Azedine Ouerghi, 2008, For Protection and Promotion: The Design and Implementation of Effective Safety Nets, World Bank, Washington DC. 
Gustafsson, Bjorn A. and Quheng, Deng, 2011, “Dibao Receipt and Its Importance for Combating Poverty in Urban China," Poverty \& Public Policy 3(1), Article 10. Hammond, Daniel R., 2009, Explaining Policy Making in the People's Republic of China: The Case of the Urban Resident Minimum Livelihood Guarantee System, 1992-2003. PhD thesis, University of Glasgow. , 2011, "Social Assistance in China, 1993-2002: Institutions, Feedback, and Policy Actors in the Chinese Policy Process," Asian Politics and Policy 3(1): 69-93. Heckman, James, Serio Urzua and Edward Vytlacil, 2006, “Understanding Instrumental Variables in Models with Essential Heterogeneity," Review of Economics and Statistics 88(3): 389-432.

Himmelfarb, Gertrude, 1984, The Idea of Poverty: England in the Early Industrial Age. London: Faber and Faber.

Holt, Stephen D., and Jennifer L. Romich, 2007, "Marginal Tax Rates Facing Low- and Moderate-Income Workers Who Participate in Means-Tested Transfer Programs," National Tax Journal 60(2): 253-276.

Kakwani, Nanak, 1986, Analyzing Redistribution Policies: A Study using Australian Data. Cambridge: Cambridge University Press.

Kanbur, Ravi, Michael Keen and Matti Tuomala, 1994, "Labor Supply and Targeting in Poverty Alleviation Programs," World Bank Economic Review 8(2): 191-211.

Kanbur, Ravi and Matti Tuomala, 2011, "Charitable Conservatism, Poverty Radicalism and Inequality Aversion,” Journal of Economic Inequality 9: 417-431.

Klebaner, Benjamin J., 1964, “Poverty and its Relief in American Thought, 1815-61,” Social Service Review 38(4): 382-399.

Krueger, Alan and Bruce Meyer, 2002, “Labor Supply Effects of Social Insurance,” In: Auerbach, A., Feldstein, M. (Eds.), Handbook of Public Economics, vol. 4. NorthHolland, Amsterdam, pp. 2393-2430.

Lemieux, Thomas and Kevin Milligan, 2008, "Incentive Effects of Social Assistance: A Regression Discontinuity Approach,” Journal of Econometrics 142(2): 807-828.

Lustig, Nora, Carola Pessino and John Scott, 2014, “The Impact of Taxes and Social Spending on Inequality and Poverty in Argentina, Bolivia, Brazil, Mexico, Peru and Uruguay: Introduction to the Special Issue," Public Finance Review 42(3): 287-303. 
Maag, Elaine, Eugene C. Steuerle, Ritadhi Chakravarti and Caleb Quakenbush, 2012, "How Marginal Tax Rates Affect Families at Various Levels of Poverty," National Tax Journal 65(4): 759-82,

Malthus, Thomas Robert, 1806, An Essay on the Principle of Population, 1890 Edition, London: Ward, Lock and Co.

Meade, James, 1972, "Poverty in the Welfare State," Oxford Economic Papers 24:289-326.

Milligan, Kevin, 2005, "Subsidizing The Stork: New Evidence On Tax Incentives And Fertility" Review of Economics and Statistics 87: 539-555.

Mirrlees, James, 1971, "An Exploration in the Theory of Optimum Income Taxation," Review of Economic Studies 38: 175-208.

Moffitt, Robert, 1992, "Incentive Effects of the US Welfare System: A Review," Journal of Economic Literature 30(1): 1-61. , 2002, "Welfare Programs and Labor Supply.” In: Auerbach, A., Feldstein, M. (Eds.), Handbook of Public Economics, vol. 4. North-Holland, Amsterdam, pp. 23932430.

Murray, Charles A., 1984. Losing Ground. American Social Policy 1950-1980. New York: Basic Books.

O'Keefe, Philip. 2004. "Social Assistance in China: An Evolving System.” World Bank, Washington, DC. Processed.

Park, Albert and Fang Cai, 2011, "The Informalization of the Chinese Labor Market," in Sarosh Kuruvilla, Ching Kwan Lee, Mary E. Gallagher (eds) From Iron Rice Bowl to Informalization, Cornell University Press.

Ravallion, Martin, 2008, “Miss-Targeting or Miss-Measurement?” Economics Letters 100: 9-12. , 2009a, "Decentralizing Eligibility for a Federal Antipoverty Program: A Case Study for China," World Bank Economic Review, 23(1): 1-30. ,2009b, "How Relevant is Targeting to the Success of the Antipoverty

Program?" World Bank Research Observer, 24(3): 205-231. , 2014a, "The Idea of Antipoverty Policy," in Handbook of Income

Distribution, Volume 2, edited by Anthony B. Atkinson and Francois Bourguignon, Amsterdam: Elsevier Science, forthcoming. 
, 2014b, "An Emerging New Form of Social Protection in $21^{\text {st }}$ Century China," in The Oxford Companion to the Economics of China, edited by Shenggen Fan, Ravi Kanbur, Shang-jin Wei, Xiaobo Zhang, Oxford: Oxford University Press.

Ravallion, Martin, Dominique van de Walle and Madhur Gaurtam, 1995, “Testing a Social Safety Net," Journal of Public Economics, 57(2): 175-199.

Raventós, Daniel, 2007, Basic Income: The Material Conditions of Freedom, London: Pluto Press.

Ricardo, David, 1817, The Principles of Political Economy and Taxation. London: Everyman Edition, 1911.

Saez, Emmanuel, 2002, “Optimal Income Transfer Programs: Intensive versus Extensive Labor Supply Responses,” Quarterly Journal of Economics 117 (3): 1039-1073.

Sahn, David and Harold Alderman, 1995, “Incentive Effects on Labor Supply of Sri Lanka’s Rice Subsidy," in Dominique van de Walle and Kimberly Nead (eds) Public Spending and the Poor, Washington DC: Johns Hopkins University Press.

Sahn, David and Stephen Younger, 2003, "Estimating the Incidence of Indirect Taxes in Developing Countries," in Francois Bourguignon Francois and Luiz Pereira Da Silva (eds) The Impact of Economic Policies on Poverty and Income Distribution: Evaluation Techniques and Tools. New York: Oxford University Press.

Skoufias, Emmanuel and Vincenzo Di Maro, 2008, "Conditional Cash Transfers, Adult Work Incentives, and Poverty," Journal of Development Studies 44(7): 935-960.

Solar, Peter M., 1995, "Poor Relief and English Economic Development before the Industrial Revolution," Economic History Review 48: 1-22.

Solinger, Dorothy, 2002, "Labour Market Reform and the Plight of the Laid-off Proletariat," The China Quarterly, 170: 304-326.

van de Walle, Dominique, 1998, “Assessing the Welfare Impacts of Public Spending,” World Development 26(3): 365-379.

Wang, Meiyan, 2007, "Emerging Urban Poverty and Effects of the Dibao Program on Alleviating Poverty in China," China \& World Economy 15: 74-88.

World Bank. 2007. Urban Dibao in China: Building on Success. Social Protection Group, East Asia Human Development Unit, World Bank, Washington, DC. 
. 2010. Social Assistance in Rural China: Tackling Poverty through Rural Dibao.

Social Protection Group, East Asia Human Development Unit, World Bank, Washington, DC. 